\title{
Innovation in grapevine water status monitoring and drought adaptation: leaf angle and temperature regulation
}

\author{
Vitale Nuzzo ${ }^{1 *}$, Davide Amato ${ }^{1}$, Nunzio Briglia ${ }^{2}$,Emmanuel Challet ${ }^{3}$, Faouzi $_{\text {Attia }}{ }^{3}$, Angelo Petrozza ${ }^{2}$, Francesco \\ Cellini' ${ }^{2}$ Giuseppe Montanaro ${ }^{1}$ \\ ${ }^{1}$ Università degli Studi della Basilicata, Dipartimento delle Culture Europee e del Mediterraneo, via Lanera, 2075100 Matera, Italy \\ ${ }^{2}$ ALSIA - Centro Ricerche Metapontum Agrobios, S.S. Ionica 106, km 448,2, 75010 Metaponto, Italy \\ ${ }^{3}$ Équipe de recherches agronomiques, Agronutrition, 3 avenue de l'Orchidée, Parc Activestre, 31390 Carbonne, France
}

\begin{abstract}
Increase of frequency, duration, and intensity of drought and heatwave and related water and heat crops stress are among the principal effects of climate change. This paper reports: (i) the effect of calcite particle film (CaPF) as a mitigation strategy against heat stress in well-watered (WW) or in drought-stress (D) conditions; and (ii) response of leaf angle variation to stomatal conductance changes induced by drought stress of Aleatico grapevine cultivar. Results have showed that CaPF, under WW conditions, reduced leaf temperature, and increased gas exchange, but, under very severe water stress, CaPF treatment was ineffective. Leaf angle ranged from $70^{\circ}$ (WW vines) to $100^{\circ}$ (drought stressed vines) and showed a good fit $\left(R^{2}=0.81\right)$ with stomatal conductance within the range of $0.25-0.05 \mathrm{~mol} \mathrm{~m}^{-2} \mathrm{~s}^{-1}$ proving it might be a reliable proxy of vine water status.
\end{abstract}

\section{Introduction}

Grapevine (Vitis vinifera L.) is a native species of the Mediterranean area where climate is characterized by dry and warm summers [1]. Lately, the Mediterranean summers show long dry periods often accompanied by heat waves [2] generating new challenges for grapevine productivity, grape and wine quality and economic sustainability of viticulture. The common way to mitigate drought effects is to irrigate, but irrigation might negatively affect grape and wine quality compared to nonirrigated vines, to the extent that a certain level of drought stress is desirable [3]. Therefore, as suggested by Medrano and co-authors [4], other management strategies should be considered to alleviate drought-induced stress before implementing irrigation.

In this context, sustainable viticulture needs (i) to effectively monitor plant water status and (ii) to improve adaptation of grapevine to drought and high temperature.

Among other strategies, foliar application of processed mineral particle films (e.g., kaolin and/or calcium carbonate) has been used in various crops to protect leaves and fruits from tissue high temperatures induced by a direct exposure to solar radiation [5]. In grapevines, kaolin particle films have been demonstrated to be effective in reducing canopy temperature [6], increasing water use efficiency [7-8], and improving some berry composition traits [9]. Processed calcium carbonate particle films $(\mathrm{CaPF})$ have received minor attention from scientific community, despite their effectiveness in mitigating leaf temperature increase also under severe drought stress conditions [10-11].
Different methods have been proposed to monitor grapevine water stress [12]. Respect to soil- or atmosphere-based methods, plant-based methods have been reported to be particularly important when choosing the irrigation strategy of the vineyard. This is mainly because they estimate plant water status as integrated response to both soil and atmosphere conditions [13].

For example, the measurement of leaf or stem water potential carried out with a Scholander-type chamber, or the stomatal conductance $\left(g_{\mathrm{s}}\right)$ measured through either a portable porometer or leaf gas exchange apparatus, are conventionally used to determine the vine water status and in turn its degree of water stress using threshold values suggested by van Leuveen et al. [14].

These methods are normally used in scientific experimental activities, with limited application in commercial vineyards, mainly because: they are time consuming and can give incorrect measurements when used by non-trained technicians [14-15].

Recently, new in vivo or image-based methods have been proposed for the estimation of the water status and other morpho-physiological and agronomic traits of the plant [16]. In particular, leaf angle is a key parameter of plant water status and leaf radiation interception to the extent it is included in energy [17] and 3-D water dynamics modelling [18]. In grapevine, leaf angle was proposed by Smart [19] as the easiest and cheapest parameter to assess the intensity of trimmed shoot transpiration. Nowadays, leaf angle is receiving increasing attention for its potential use in irrigation scheduling [20]. Correlative information between leaf water potential and leaf angle in grapevine has been the subject of recent studies [21], however how variation of

* Corresponding author: vitale.nuzzo@unibas.it 
$g_{\text {s }}$ could modulate the leaf angle was not adequately explored. Therefore, the first objective of this study was to examine the variation of leaf angle (manual and imagebased methods) concurrently with that of $g_{\mathrm{s}}$.

The second objective was to integrate current knowledge on the effects of a thermoregulatory compound (e.g., $\mathrm{CaPF}[10])$ in well-watered and in drought stressed conditions.

\section{Materials and Methods}

\subsection{Experiment 1}

\subsubsection{Site, plant material and experimental design}

The trial was carried out at the 'Metapontum Agrobios' Research Centre of the Basilicata Agency for Innovation in Agriculture (ALSIA), located in Metaponto, Southern Italy $\left(40^{\circ} 23^{\prime} 31.4{ }^{\prime} ' \mathrm{~N}, 16^{\circ} 47^{\prime} 10.9^{\prime}\right.$ ' $\left.\mathrm{E}\right)$ during the summer 2018.

A total of 48 five-year-old Merlot (Vitis vinifera L.) vines grafted onto SO4 rootstock were grown in $20 \mathrm{~L} \mathrm{PVC}$ pots, drip irrigated and weekly fertilised.

The experiment started at veraison (28th June, 81 $\mathrm{BBCH}$ stage) - hereafter referred to as 0 days after treatment (DAT) - by grouping vines according to irrigation water (W, Factor 1). Namely, 24 vines continued to be well watered (WW) by receiving $100 \%$ of daily water consumption, while the other 24 vines were subjected to drought (D), receiving, on a daily basis, $25 \%$ of the water supplied to WW vines. The experiment ended after 15 days when the irrigation was resumed for all vines ensuring soil moisture at field capacity.

Following a $2^{2}$ factorial experimental design, the WW and $\mathrm{D}$ vines were further split based on the application of the calcite particle film (CaPF, Factor 2), with 12 vines per treatment being grouped. The treatments were: WW (well-watered, no calcite received), D (drought conditions, no calcite received), $\mathrm{WW}+\mathrm{CaPF}$ (wellwatered, calcite received), $\mathrm{D}+\mathrm{CaPF}$ (drought conditions, calcite received). The $\mathrm{CaPF}$ was sprayed in a single application on 28th June (0 DAT) as a $3 \%$ vol aqueous solution and without any surfactant according to the product label. The CaPF was the commercial Turn-on $\AA$, sourced by Agronutrition (Carbonne, France), which is a processed calcite-silicon mediated particle film.

\subsubsection{Stem water potential, leaf gas exchange and leaf temperature}

Stem water potential was determined on DAT 15 around midday (from 11:30 to 13:30) using a Scholander type pressure chamber (model 600, PMS Instruments, Corvallis, OR, USA) which was pressurized with nitrogen [22]. One fully expanded leaf per vine (3 vines per treatment) was sampled on the middle part of the main shoot. Leaf gas exchange measurements were also performed on DAT 15 around midday using a portable photosynthesis system Li-Cor 6400-02B and LED light source (Li-Cor, Inc., Lincoln, NE, USA), equipped with a leaf chamber $3 \times 2 \mathrm{~cm}^{2}$ wide. Measurements were carried out, on 2-3 fully expanded and well exposed leaves belonging to 4 vines per treatment, placed at mid-shoot height, under constant and saturating light condition (PAR $=1000 \mu \mathrm{mol} \mathrm{m} \mathrm{m}^{-2} \mathrm{~s}^{-1}$ ), while temperature and $\mathrm{CO}_{2}$ concentration were maintained at the prevailing environmental condition, and the operating flow rate at $500 \mu \mathrm{mol} \mathrm{s}{ }^{-1}$.

Air and leaf temperature were measured by means of a thermocouple on the leaf clip holder 2030-B of the PAM 2500 fluoremeter (Walz, GmbH, Effeltrich, Germany). Measurements were carried out around midday on the same vines used for gas exchange measurements. Three well exposed main leaves per vine were sampled, and the temperature was measured from the central part of the leaf lamina.

\subsection{Experiment 2}

\subsubsection{Site, plant material and experimental design}

The experiment was conducted at the National Plant Phenomics Centre, IBERS-Aberystwyth University, United Kingdom $\left(52^{\circ} 24^{\prime} \mathrm{N} ;-4^{\circ} 01^{\prime}\right.$ E) during summer 2018 in a greenhouse with controlled environmental conditions. The minimum air temperature was set at $18^{\circ} \mathrm{C}$ and active radiation (PAR) at approximately $800 \mu \mathrm{mol} \mathrm{m}$ $2 \mathrm{~s}^{-1}$ (natural light supplemented with $600 \mathrm{~W}$ sodium lamps) from 05:00 to 20:00 h.

A total of 45 vines (cv Aleatico) grafted on 110R rootstock were grown in black 3.5 L PVC pots filled with a $3: 1 \mathrm{v} / \mathrm{v}$ mixture of sandy loam soil. Vines were irrigated and weekly fertilized. The imposition of irrigation treatments started on the $21^{\text {st }}$ of May (55 BBCH-scale) hereafter referred as 0 day after treatment (DAT).

At Day 0, 15 vines were allocated to each of 3 irrigation treatments (fraction of water to be replenished via irrigation): restoring 100\% (control, I100), 60\% (I60) and $30 \%$ (I30) of the available soil water content.

\subsubsection{Stomatal Conductance and leaf angle}

Stomatal conductance was measured around midday (11:30-12:30 h) using a portable porometer (DeltaDevice AP4). The measurements were performed on 4- 5 vines per irrigation treatment on two fully expanded leaves per vine selected from the apical, middle and basal region of the main plant canopy (nodes 6-11 from the ground).

Leaf angle was measured as reported in [21].

\section{Results and Discussions}

In this paper, data of the last day of the two drought trials are presented, when, in both experiments, plants had reached the maximum water stress level and, consequently, a wider variability of data among treatments was recorded. 


\subsection{Experiment 1}

Potted vines of Merlot/SO4 in well-watered (WW) conditions responded positively to the $+\mathrm{CaPF}$ treatment maintaining an assimilation rate and a stomatal conductance significantly higher than those of non-treated vines (Fig. 1). Instead, water deficit have reduced assimilation rate near compensation point and the stomatal conductance well below $0.05 \mathrm{~mol} \mathrm{~m}^{-2} \mathrm{~s}^{-1}$, without significant difference between $\mathrm{CaPF}$ sprayed and unsprayed vines (Fig. 1).

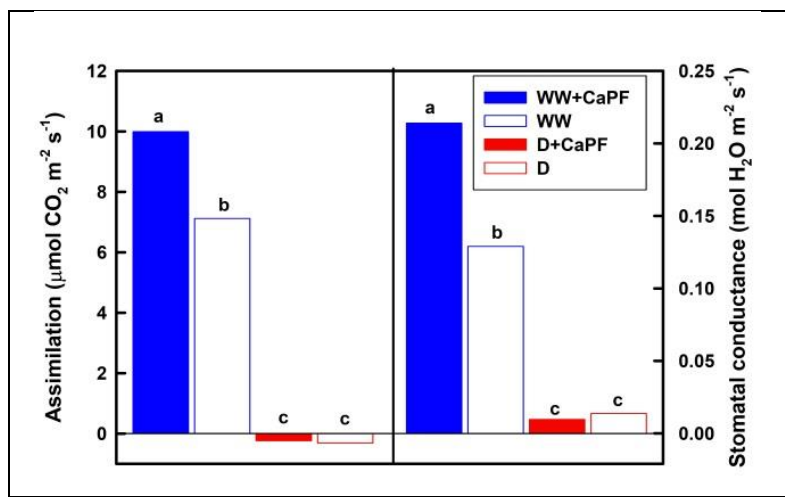

Fig. 1. Assimilation rate and stomatal conductance measured around noon in sprayed $(+\mathrm{CaPF})$ and non-sprayed and in wellwatered (WW) and drought stressed (D) potted plants of Merlot/SO4. Measurements were done at $33.8{ }^{\circ} \mathrm{C}$ air temperature, $33.3 \%$ relative humidity, $917 \mathrm{~W} \mathrm{~m}^{-2}$ global radiation and $3.63 \mathrm{kPa}$ VPD. Each bar is the average of 30-40 single measurements. Comparing treatments within the same parameter different letters indicate statistically significant difference at $p=0.05$ or 0.01 (Holm-Sidak multiple comparisons test).

$\mathrm{WW}+\mathrm{CaPF}$ Merlot/SO4 vines showed values of stomatal conductance and assimilation similar to those proposed by Medrano et al. [23] for non-water-stressed vines. While non sprayed WW vines were in the range of moderate water stress $[23,12]$.

In WW conditions, the significant higher gas exchange parameter of $+\mathrm{CaPF}$ respect to $-\mathrm{CaPF}$ could be attributable to the significant lower leaf temperature measured on WW+CaPF leaves respect to WW (Fig. 2). It has been suggested that the application of particle-film may enhance the reflectance of solar radiation and, changing the radiative properties of the leaf, it mitigates the impact of heat stress on leaf and fruit [5].

In fact, in WW conditions, leaf temperature was almost $3^{\circ} \mathrm{C}$ and $1.5^{\circ} \mathrm{C}$ lower than air temperature, in $+\mathrm{CaPF}$ and $-\mathrm{CaPF}$ vines, respectively. While, in $\mathrm{D}$ conditions leaf temperature was higher than air temperature (Fig. 2).

In drought conditions a negative assimilation rate and a very low stomatal conductance were observed, without significant differences between $+\mathrm{CaPF}$ and $-\mathrm{CaPF}$ vines were found in all the parameters measured (Figs. 1, 2).

\subsection{Experiment 2}

This experiment was specifically designed to measure and to compare the variation of leaf angle in grapevine submitted to different level of water stress.

The different volume of irrigation water returned daily to the three groups of vines (i.e., I100, I60, I30) significantly differentiated the measured physiological traits and the leaf angle (Tab. 1). The resulting water status level of each group might be defined optimal (I100), mild water stress (I60) and severe water stress [12, $14,23]$.

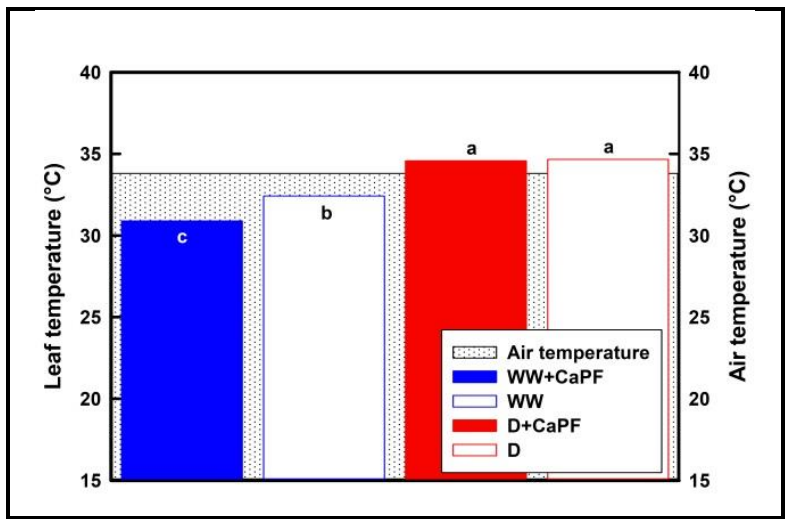

Fig. 2. Average leaf temperature $(n=36)$ and mean air temperature measured around midday in potted Merlot/SO4 vines. Different letters indicate statistically significant differences $(p$-value $=0.05$; Holm-Sidak multiple comparisons test).

Table 1. Some eco-physiological parameter measured around midday, at the date of maximum stress level on potted vines of

Aleatico/110R. All parameters were measured in leaves situated in the middle part of the shoot. Comparing treatments within the same parameter, different lower case letters indicate statistically significant differences; Comparing leaf angle positions different upper case letters indicate statistically significant differences $(p$-value $=0.05$; Holm-Sidak multiple comparisons test).

\begin{tabular}{|c|c|c|c|}
\hline Parameter & $\mathrm{I} 100$ & $\mathrm{I} 60$ & $\mathrm{I} 30$ \\
\hline $\begin{array}{c}\text { Xylem water potential } \\
(\mathrm{MPa})\end{array}$ & $-0.39 \mathrm{a}$ & $-0.56 \mathrm{a}$ & $-1.12 \mathrm{~b}$ \\
\hline $\begin{array}{c}\text { Stomatal conductance } \\
\left(\mathrm{mol} \mathrm{m}^{-2} \mathrm{~s}^{-1}\right)\end{array}$ & $0.21 \mathrm{a}$ & $0.11 \mathrm{~b}$ & $0.05 \mathrm{c}$ \\
\hline Leaf angle apical $\left(^{\circ}\right)$ & $78 \mathrm{c}, \mathrm{A}$ & $86 \mathrm{~b}, \mathrm{~A}$ & $98 \mathrm{a}, \mathrm{A}$ \\
\hline Leaf angle middle $\left(^{\circ}\right)$ & $74 \mathrm{c}, \mathrm{A}$ & $85 \mathrm{~b}, \mathrm{~A}$ & $100 \mathrm{a}, \mathrm{A}$ \\
\hline Leaf angle basal $\left(^{\circ}\right)$ & $76 \mathrm{c}, \mathrm{A}$ & $85 \mathrm{~b}, \mathrm{~A}$ & $96 \mathrm{a}, \mathrm{A}$ \\
\hline
\end{tabular}

\subsection{Leaf angle and stomatal conductance}

The leaf angle varied from about $70^{\circ}$ to $100^{\circ}$ for wellwatered and drought stressed conditions, respectively a larger range (from $30^{\circ}$ to about $90^{\circ}$ ) was observed by 
Smart [19]. The difference could be related to the different experimental conditions [19].

Stomatal conductance decreased and leaf angle increased due to the progress of water stress in Aleatico cultivar showing a good linear fit $\left(R^{2}=0.81\right)$ (Fig. 3). Such correlation should be tested under more severe water stress. In addition, considering the cv-specific arrangement of the leaves along the shoot $[24,25]$, the leaf angle VS $g_{\mathrm{s}}$ correlation should be examined in various cv for possible generalization.

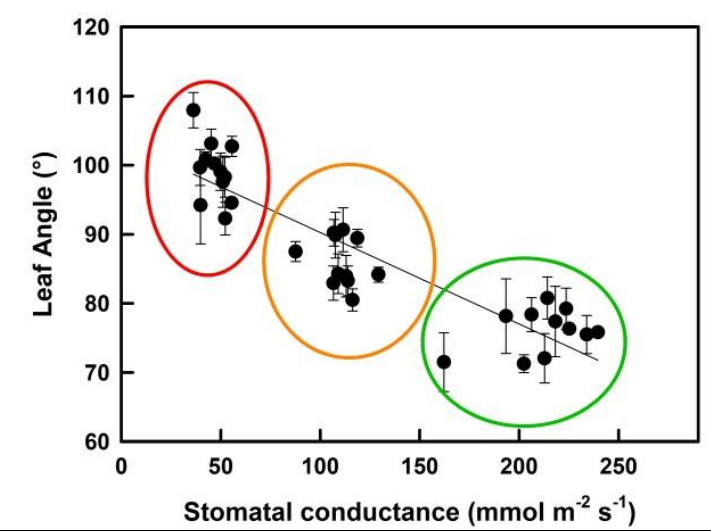

Fig. 3. Relationship between leaf angle, and stomatal conductance. Regression line was significant at $p<0.0001$ ( $\mathrm{y}=$ $\mathrm{y}_{0}+\mathrm{b}^{*} \mathrm{x}$. The parameters estimated by the non-linear fitting were: $\mathrm{y}_{0}=103.49 ; \mathrm{b}=-0.13$. All were significant at $p<0.0001$. Single measurements have been grouped in circles according to the ranges of stomatal conductance proposed by Medrano et al. [23] for no water stress to mild (green); mild to moderate (orange) and moderate to severe water stress (red), respectively.

\section{Conclusions}

This paper reports more evidences on the influence of drought on grapevine gas exchange and suggest that the use of calcite particle films even in well water conditions might reduce leaf temperature in summer, improving the overall leaf functioning.

Based on the significant relationship between $g_{\mathrm{s}}$ and leaf angle, it might be concluded that leaf angle is a promising proxy of plant water status.

The study was partially founded by PSR Basilicata 2014-2020, project: PROSIT (CUP H86G18000080002) and IN.VINI.VE.RI.T.A.S. (CUP G64D20000000006). Authors acknowledge Agronutrition for providing the $\mathrm{CaPF}$ (Turn-on ${ }^{\circledR}$ ).

\section{References}

1. L. E. Williams, M. A. Matthews. Grapevine. p. 10191055. In: Irrigation of Agricultural Crops. B.A. Stewart and D.R. Nielsen (Eds.), Agronomy Monograph No. 30. ASA-CSSA-SSSA, Madison, WI. (1990)

2. Intergovernmental Panel on Climate Change. Climate Change 2014 - Impacts, adaptation and vulnerability: regional aspects. Cambridge University Press (2014)
3. M. M. Chaves, O. Zarrouk, R. Francisco, J. M. Costa, T. Santos, A. P. Regalado, M. L. Rodrigues, C. M. Lopes. An. Bot. 105, 661-676 (2010)

4. H. Medrano, M. Tomás, S. Martorell, J. M. Escalona, A. Pou, S. Fuentes, J. Flexas, and J. Bota. Agronomy for Sustainable Development, 35(2), 499-517 (2015)

5. D. M. Glenn, G. J. Puterka. Horticultural reviews, 31, 1-44 (2004)

6. N. M. Cooley, D. M. Glenn, P. R. Clingeleffer, R. Walker. Acta Hortic. 792, 193-199 (2008)

7. D. M. Glenn, N. Cooley, R. Walker, P. R. Clingeleffer, K. C. Shellie. Hortscience, 45, 1178 1187 (2010)

8. L. Brillante, N. Belfiore, F. Gaiotti, L. Lovat, L. Sansone, S. Poni, D. Tomasi. PLoS ONE, 11(6), e0156631 (2016)

9. C. Ou, X. Du, K. Shellie, C. Ross, M. C. Qian. J. Agric. Food Chem. 58, 12890-12898 (2010)

10. D. Amato, G. Montanaro, S Summerer, F. Attia, E. Challet, V. Nuzzo. OenoOne 54, 4, 1007-10201020 (2020)

11. F. Attia, L. Martinez, T. Lamaze. J. Inter. Sc.Vigne Vin, 48, 237-245 (2014)

12. M. Rienth, T. Scholasch. OenoOne. 53.4.2403 (2019)

13. H. G. Jones. J. Exp. Bot., 55, 2427-2436 (2004)

14. C. van Leeuwen, P. Pieri, P. Vivin. Comparison of three operational tools for the assessment of vine water status: stem water potential, carbon isotope discrimination measured on grape sugar and water balance. In: Methodologies and results in Grapevine Research, Delrot S, Medrano H, Or E, Bavaresco L. and Grando S. Editors, Springer, Science \& Business Media B.V., 87-106 (2010)

15. J. E. Fernández. Agric. Water Manage, 142, 99-109 (2014)

16. D. Chen, K. Neumann, S. Friedel, B. Kilian, M. Chen, T. Altmann, C. Klukas. Plant Cell, 26, 46364655 (2014)

17. D. D. Baldocchi, B. A. Hutchison, D. R. Matt, R T . McMillen. J. Appl. Ecol., 22, 539-555 (1985)

18. J. Zhu, Z. Dai, P Vivin, G. A. Gambetta, M. Henke, A. Peccoux. Ann. Bot. 18, 833-848. (2018)

19. R. E. Smart. Amer. J. Enol. Viticult., 25, 84-91 (1974)

20. R. B. G. da Silva, M. M. Gabira, D. Zanoni do Prado, G. Uesugi, D. Simões, M. R. da Silva. Forest, 11, 1198 (2020)

21. N. Briglia, K. Williams, D. Wu, Y. Li, S. Tao, F. Corke, G. Montanaro, A. Petrozza, D. Amato, F. Cellini, J. H. Doonan, W. Yang, V. Nuzzo. Front. Plant Sci. 11, 595 (2020).

22. N. C. Turner. Plant and Soil, 58, 339-366. (1981)

23. H. Medrano, J. M. Escalona, J. Bota, J. Gulías, J. Flexas. An. Bot., 89, 895-905 (2002)

24. A. Palliotti, O. Silvestroni, D. Petoumenou. Amer. J. Enol. Vitic., 60, 189-198 (2009). 
25. D. S. Falster, M. Westoby. New Phytol., 158, 509525 (2003). 